\title{
A study of the catalytic properties of mesoporous silica doped with dysprosium and modified with copper on the example of xylene hydrogenation
}

\author{
(C) Alexander A. Tokranov, ${ }^{+}$Elena O. Filippova, Roman V. Shafigulin, ${ }^{*}$ \\ Alexander A. Shmelev, and Andzhela V. Bulanova* \\ Physical Chemistry Division. Institute of Natural Sciences. Samara University. Moskovskoye Ave., 34. \\ Samara, 423086. Russia.Phone: +7 (846) 334-54-47.E-mail: grekopop182@gmail.ru
}

\begin{abstract}
*Supervising author; ${ }^{+}$Corresponding author Keywords: mesoporous silica, template synthesis, hydrogenation of xylenes.
\end{abstract}

\begin{abstract}
Catalytic hydrogenation of aromatic hydrocarbons is one of the most important reactions in industry. The use of copper as a modifier of silica is beneficial both from an economic point of view and from the point of view of ease of modification. The catalytic properties of a mesoporous structured material modified by copper $(\mathrm{Cu} / \mathrm{MCM})$ and a mesoporous structured material $(\mathrm{MCM})$ doped with dysprosium and modified copper (Dy$\mathrm{Cu} / \mathrm{MCM}$ ) synthesized by the template method were studied in xylene hydrogenation reactions. The textural characteristics of the catalysts obtained were studied by low-temperature nitrogen adsorption-desorption, ICP, XRF, XRD, SEM, TEM. To determine the specific surface area, the BET model was used with a relative partial pressure $\mathrm{P} / \mathrm{P}_{0}$ 0.05-0.3. The total pore volume and size distribution of meso- and macroporous was calculated from the desorption curve using the BJH model. With the help of the ICP-method, the metals were also quantitatively determined using the absolute calibration method. For the analysis of microporous, the DFT density functional method was used. The study of the kinetics of hydrogenation of $o, m, p$-xylenes was carried out in the temperature range $130-170^{\circ} \mathrm{C}$ and a hydrogen pressure of $3 \mathrm{~atm}$. The kinetics of gas-phase hydrogenation reactions was studied in a static mode using the method of gas chromatography, on the original setup, which allows on-line analysis of the reaction mixture. The xylene conversions on $\mathrm{Cu} / \mathrm{MCM}$ and $\mathrm{Dy}-\mathrm{Cu} / \mathrm{MCM}$ catalysts are calculated at various reaction temperatures.
\end{abstract}

\section{References}

[1] S.I. Karpov, et al. Prospects for the synthesis and use of ordered mesoporous materials in sorptionchromatographic analysis, separation and concentration of physiologically active substances. Sorption and Chromatographic Processes. 2013. Vol.13. No.2. P.125-140. (russian)

[2] S. Liu et al. Optimization of online upgrading of bio-oil with MCM-41 and catalyst durability analysis. Chemistry and Industry of Forest Products. 2016. Vol.36. No.4. P.55-63.

[3] W. Chen et al. Effective mineralization of diclofenac by catalytic ozonation using Fe-MCM-41 catalyst. Chemical Engineering Journal. 2016. Vol.304. P.594-601.

[4] E.O. Filippova, R.V. Shafigulin, A.A. Shmelev, Yu.S. Pleshakova, A.V. Bulanova. Study of the sorption properties of mesoporous silica by the method of reverse gas chromatography Butlerov Communications. 2017. Vol.52. No.12. P.159-165. DOI: 10.37952/ROI-jbc-01/17-52-12-159

[5] Sh. Sohrabnezhad, A. Jafarzadeh, A. Pourahmad. Synthesis and characterization of MCM-41 ropes. Materials Letters. 2018. Vol.212. P.16-19.

[6] J.V. Faustova et al. Adsorption properties of surface layers of silica gel modified by transition metal acetylacetonates. Bulletin of the Moscow State Technical University. NE Bauman. Series "Natural Sciences". 2018. No.2. P.77. (russian)

[7] R.V. Shafigulin et al. Mesoporous Silica Doped with Dysprosium and Modified with Nickel: A Highly Efficient and Heterogeneous Catalyst for the Hydrogenation of Benzene, Ethylbenzene and Xylenes. Catalysis Letters. 2019. Vol.149. No.4. P.916-928.

[8] A.A. Bernardes, C.A. Emanuelli, Patrícia Cofferri, Antonio Marchi Netto, Márcia S.L. Miranda, Rodrigo Brambilla, João Henrique Z. dos Santos. Octadecyl-modified silicas obtained by non-hydrolytic condensation of a C18-hybrid silica sol on a silica surface. Journal of Non-Crystalline Solids. 2017. Vol.466-467. P.8-14. 
[9] J. Gañán, S. Morante-Zarcero, D. Pérez-Quintanilla, I. Sierra. Evaluation of mesoporous imprinted silicas as MSPD selective sorbents of ketoprofen in powder milk. Materials Letters. 2017. Vol.2. No.127. P.5-7.

[10] J. Alimunnisa, K. Ravichandran, K.S. Meena. Synthesis and characterization of Ag@ $\mathrm{SiO}_{2}$ core-shell nanoparticles for antibacterial and environmental applications. Journal of Molecular Liquids. 2017. Vol.231. P.281-287.

[11] Tieliang Liu, Fang Jin, Xianqiao Wang, Yangchun Fan, Ming Yuan. Synthesis of titanium containing MCM-41 from industrial hexafluorosilicic acid as epoxidation catalyst. Catalysis Today. 2017. Vol.282. P.140-150.

[12] Y. Feng et al. Mesoporous Sn(IV) doping MCM-41 supported Pd nanoparticles for enhanced selective catalytic oxidation of 1, 2-propanediol to pyruvic acid. Applied Catalysis B: Environmental. 2019. Vol.253. P.111-120.

[13] B.M. Daas, S. Ghosh. Catalytic ability of novel Pt/MCM-41 for fuel cells. Journal of the Iranian Chemical Society. 2018. Vol.15. No.4. P.987-996. 